\title{
EDITORIAL
}

\section{Emergency medicine certification in Canada: the years march on but the questions remain the same}

\author{
Riyad B. Abu-Laban, MD, MHSc
}

\begin{abstract}
See related article on Page 108
\end{abstract}
Version françAISE À LA PAGE 104

$\mathbf{I}_{8}^{\mathrm{n}}$ n 1987, I found myself in the painful situation of struggling to answer a key question during a residency application interview. The question: what did I feel were the differences between the Royal College emergency medicine fellowship program, FRCP(EM), and the CCFP(EM) program of the College of Family Physicians of Canada. My uncertainty regarding Canadian EM certification routes was patently evident. Following that unpleasant interview, I worked full-time in EM for several years with a general license, completed a Royal College EM residency and obtained a masters degree in epidemiology. Now, 2 decades later, I am a researcher and emergency physician (EP) at Vancouver General Hospital, a tertiary trauma centre and a base hospital for a Royal College EM residency program. I teach medical students during most of my emergency department (ED) shifts, and sometimes the students interested in EM ask me the same question that I was asked in 1987. And guess what? I still struggle to answer it with any clarity, much less with any conviction. Perhaps it is time to ask why.

Canada is the only country with 2 colleges governing EM certification, yet fundamental questions regarding our system remain difficult to answer. Each college has published goals for its program, and each curriculum appears consistent with those goals. But do 2 independently managed training programs provide the optimal solution for Canada? Do they prepare physicians with different aspirations to pursue different career paths? The evidence indicates that the answer to these critical questions is a resounding "no." In my view the inconsistencies, redundancies and inefficiencies in our current system make suboptimal use of our scarce human and educational resources. Beyond this, I believe the divided voice that results from our 2 routes of certification has become an increasing impediment to both our development as a specialty and our political strength. Despite these issues, we remain paralyzed at the prospect of reforming our 2-college system, even though its evolution and perpetuation have more to do with politics and market forces than with vision or standards.

The history of our 2 certification streams is well described,,$^{1-3}$ but questioning the bizarre Canadian approach to EM training is nothing new. Back in the days of the CAEP Communiqué (a newsletter that preceded CJEM), there was vigorous debate regarding fundamental questions about EM training and certification. ${ }^{4-9}$ In 1998, the Canadian Association of Emergency Physicians (CAEP) struck a task force to examine this very issue. ${ }^{10}$ Our inability to reach consensus in the past should not preclude us from revisiting these issues. EM is very different than it was a decade ago; we are now firmly established and accepted as a specialty. Several Canadian universities have departments of EM, and EM training is now a core rotation in most medical schools. Although a significant proportion of emergency care in Canada is and will continue to be provided by family physicians without EM certification or formal training, certification is the norm for new physicians intending to pursue a career as a full-time EP. Positions in almost all academic and large community centres now mandate some form of EM certification. This mandate has not arisen out of self-justification but because of increases in the scope and complexity of standard ED care.

Our terminology is central to discussing the problems

From the Department of Emergency Medicine, Vancouver General Hospital, Vancouver, BC

All editorial matter represents the views of the authors and not necessarily those of CJEM or the Canadian Association of Emergency Physicians.

CJEM 2008;10(2):101-3 
with EM in Canada. We have avoided defining such things as "delivering EM care," "being an EP" and "being an EM specialist." CAEP has understandably taken an inclusive approach to date, and, despite its name, defines itself as the "national voice of emergency medicine" (rather than the national voice of emergency physicians). ${ }^{11}$ Avoiding unnecessary distinctions makes sense when a specialty is young. However, EM certification has now existed for a quarter century in Canada, and clarity of terminology is important if we are ever to have a united voice and defined standards. Surely the time has come to acknowledge that not everyone who delivers EM care is an EP, just like not everyone who delivers a baby is an obstetrician. The fact that excellent EM care is provided every day across Canada by physicians from a range of backgrounds is indisputable. ${ }^{12}$ However, in all established fields of medicine the name of a specialty must eventually become synonymous with certification. For example, a "cardiologist" is, by definition, certified in cardiology. Are we not at the point where providing optimal care by certified EPs in all but the smallest EDs should be our objective? Should this not, therefore, be championed by CAEP as a national goal to be met within a specified time frame?

Although many physicians (myself included, in my preresidency years) developed EM expertise "on the job" and without training, such an approach is not ideal. Our collective silence on the issue of EM certification contrasts with the position of the American College of Emergency Physicians, and gives tacit approval for future EPs to develop their skills in this same manner. Some may argue that we don't have the resources to train enough EPs to meet Canada's future needs. However, rather than a reason to avoid endorsing an appropriate standard, this is a reason to vigorously advocate for more training slots (something an appropriate standard would facilitate). The 2002 CAEP submission to the Romanow Comission called for a "minimum basic skill set for all health professionals" in Canadian EDs. ${ }^{13}$ Endorsing certification in EM is the appropriate way of defining such a skill set.

The question of who we call an "EM specialist" is potentially divisive, and in my view has been a significant factor in the delay of CAEP's evolution to function as the specialty society we increasingly require. In contrast to the Royal College program, CCFP(EM) training was intended to improve the ED care delivered by family physicians through "special competence" training, not to produce career EPs. ${ }^{1,14}$ But studies have shown that the overwhelming majority of $\mathrm{CCFP}(\mathrm{EM})$ graduates practise full-time EM with little or no family medicine. ${ }^{15,16}$ Many of Canada's leading EM clinicians, educators, researchers and administrators are CCFP(EM)s. They are EM "specialists" in every sense of the word except the technical one, as provincial colleges reserve this designation for FRCPs. Moreover, although CCFP(EM)s comprise the majority of Canada's certified EPs, they are ostensibly represented by a college with a primary focus on family medicine and no mandate to produce EM specialists. Given this situation, it is not surprising that some CCFP(EM)s have proclaimed that they feel like "second class citizens," underscores the current division in our specialty. Similarly, I believe many Royal College trained EPs are deeply troubled at suggestions that jobs with an FRCP minimum requirement are "elitist," and the belief, by some, that after an arbitrary number of years any benefit from their additional education is negated. Proponents of such concepts often make the regressive proposal that despite the standardized curriculum and validated evaluation that a specialty establishes, job applicants should be judged individually, solely on subjective merits, rather than face a credential hurdle. It is clear that frustrations with our current system exist for graduates of both training streams.

There remain inadequate resources to train EPs in Canada. ${ }^{13,18,19}$ To use these resources efficiently and effectively, we must strive to match the educational experience with the intended practice at the level of each individual resident. A resource misallocation occurs every time a future $\mathrm{EP}$ in a CCFP(EM) program spends the first 2 years of his or her education developing an expertise in office-based family medicine; this is expertise that he or she will likely never use, at the expense of a curriculum thoughtfully designed for a career in EM. Meanwhile, the extra years of the Royal College program are in part touted as a route to develop nonclinical EM expertise, as 5 years of training is not required to produce an excellent EM clinician. ${ }^{2}$ But many FRCP residents do not take advantage of this opportunity. Thus every time a future EP in a Royal College program graduates without additional nonclinical expertise, or with expertise that they fail to apply, a resource misallocation has also occurred.

In my view, we are long overdue for changes to produce a united and strong EM specialty with well-allocated resources, thus optimizing ED care for Canadians. Achieving this requires leadership, which I believe must come from CAEP. A task force should be re-established to review the history of prior CAEP initiatives in this area, consult widely, bring the key parties together and broker an acceptable solution. Both colleges must be willing to compromise, and must set aside their vested interests in a principled effort to retool the system. During this process, I suggest we be mindful of the wisdom of Grant Innes, the 
first Editor-in-Chief of CJEM. He wrote a provocative editorial in 2002 listing some of the countless skills EPs must possess and stated that Family Physicians and Emergency Physicians are not the same and are not interchangeable. ${ }^{20}$ In keeping with this, and despite the fact that family medicine and emergency medicine will always have overlaps and close linkages, it makes no sense for career EPs to be trained and certified by the College of Family Physicians of Canada. Nor does it make sense to create a separate EM college or CAEP fellowship, as some have proposed. ${ }^{6,17}$ The Royal College of Physicians and Surgeons was established in 1929 by a special act of parliament to oversee the education of specialists in Canada, ${ }^{21}$ and the strides EM has made through our affiliation with the Royal College are innumerable. It is within the Royal College that a reformed coordination of EP education and certification should reside. My proposed solution is similar to that put forward by many people previously: a common stream curriculum of an appropriate length ( 3 or at most 4 years) leading to a specialization in clinical EM, followed by the option of 1 or 2 fellowship years for those who are more academically inclined. ${ }^{1,22}$ The pros and cons of a limited window of practice eligibility access to the exams for the common stream should also be carefully considered.

Nine years ago, in the inaugural issue of CJEM, a paper was published entitled "Emergency Medicine Training in Canada." The authors concluded "Our citizens deserve one standardized, certified, accredited EM training program that produces the highest quality emergency physicians." I couldn't agree more, and I think it's high time we got on with it.

Competing interests: Dr. Riyad B. Abu-Laban has FRCP(C) emergency medicine certification and is a Fellow of Royal College of Physicians and Surgeons of Canada. He holds an appointment as an assistant professor in the Department of Surgery at the University of British Columbia.

Keywords: emergency medicine, certification, training, residency, standards, education

\section{References}

1. Moore K, Lucky C. Emegency medicine training in Canada. CJEM 1999;1:51-3.

2. Ducharme J. Preparing emergency physicians for the future. CMAJ 2003;168:1548-9.

3. Steiner IP. Emergency medicine practise and training in Canada. CMAJ 2003;168:1549-50.
4. Ducharme J, Innes G. The FRCPC vs CCFP(EM): Is there a difference 10 years after residency? CAEP Communiqué 1997;Fall:1-4.

5. The FRCPC vs CCFP(EM) [letters]. See exchange of letters in: CAEP Communiqué 1997-98; Winter:7-13.

6. Etherington J. An immodest proposal: the future of emergency medicine training in Canada. CAEP Communiqué 1997-98; Winter:16-9.

7. The FRCPC vs CCFP(EM) [letters]. See exchange of letters in: CAEP Communiqué 1998;:Spring:7-9.

8. On unified EM training [letters]. See exchange of letters in: CAEP Communiqué 1998;Summer:7-11.

9. Gray S. Emergency medicine residency training [letter]. CAEP Communiqué 1998;Fall:5.

10. Grunfeld AF. The task force on emergency medicine training. CAEP Communiqué 1998;Summer:1-2.

11. About CAEP. Canadian Association of Emergency Physician. Available: www.caep.ca (accessed 2008 Jan 19).

12. Lund A. I am emergency medicine [letter]. CJEM 2006;8:4-5.

13. CAEP Working Group on the Future of Emergency Medicine in Canada. The future of emergency medicine in Canada: submission from CAEP to the Romanow Commission. Part 1. CJEM 2002;4:359-68.

14. Exams and Certification. The College of Family Physicians of Canada. Available: www.cfpc.ca (accessed 2008 Jan 19)

15. Chan BT. Do family physicians with emergency medicine certification actually practise family medicine. CMAJ 2002;167:869-70.

16. Shepherd LG, Burden JK. A survey of one CCFP-EM program's graduates: their background, intended type of practice and actual practice. CJEM 2005;7:315-20.

17. Campbell S. CCFP-EM versus FRCP [letter]. CJEM 2003;5:80.

18. Steiner IP, Yoon PW, Holroyd BR. Manpower crisis in emergency medicine: Can residency programs make an impact? CJEM 2000;2:103-5.

19. CAEP Working Group on the Future of Emergency Medicine in Canada. The future of emergency medicine in Canada: submission from CAEP to the Romanow Commission. Part 2. CJEM 2002;4:431-8.

20. Innes G. Thinking outside the box. CJEM 2002;4:316.

21. About The College. The Royal College of Physicians and Surgeons of Canada. Available: http://rcpsc.medical.org (accessed 2008 Jan 19).

22. MacDonald RD. How to train emergency docs. CMAJ 2003; 169:389.

Correspondence to: Dr. Riyad Abu-Laban, Department of Emergency Medicine, Vancouver General Hospital, 855 West 12th Ave., Vancouver BC V5Z1M9; abulaban@interchange.ubc.ca 